\title{
Leyendo a Spallanzani hoy en día
}

\section{Reading Spallanzani today}

Walter Ledermann $D .^{1}$

'Centro de Estudios Humanistas Julio Prado.

Recibido: 30 de enero de 2020

\section{Resumen}

Recordamos al abate Lázaro Spallanzani (1729-1799) fundamentalmente por su victoriosa contienda con Needham sobre la generación espontánea, pero fue un hombre de múltiples intereses en distintos campos de la ciencia, desde la biología a la volcanología. Se lo llamó el "biólogo de los biólogos", desarrollando una serie de investigaciones sobre la reproducción de los anfibios, en una de las cuales - "Experiencias al servicio de la historia de la generación de animales y plantas" - el lector moderno se estremece de horror ante las crueles mutilaciones que infligiera a los sapos machos tratando de interrumpir su copulación con las hembras. Él mismo las califica de "bárbaras" estas torturas, inadmisibles en un hombre que detentaba una jerarquía eclesiástica, aún en una época como la suya, en que se calificaba a los animales como "anima vili" (cosa sin valor). Mucho se ha avanzado hoy en día en resguardo de nuestros "hermanos menores", como los llamara San Francisco, pero aún falta mucho que hacer en la regulación de la experimentación científica que los utiliza.

Palabras clave: Spallanzani; sapo; fecundación; sufrimiento animal.

$\mathrm{M}$ ucho se ha escrito acerca de este singular investigador italiano, que la mayoría de nuestros colegas relaciona vagamente con la teoría de la generación espontánea, cuya existencia buscó por un tiempo, para terminar atacándola con tal denuedo que terminó por sumirla en el ridículo, tanto a ella como a su defensor Needham. De toda dicha escritura -que era italiano, que vivió 70 años en el siglo XVIII, que su padre quería que fuese abogado, que era investigador tenaz pero descuidado, que se interesó en la fecundación y en esto y esto otro- destacamos y queremos analizar tres hechos: su pasión por la biología (lo llamaron "el biólogo de los biólogos"), su calidad de eclesiástico (era abate) y su inaudita crueldad con los

\begin{abstract}
We remember Lazaro Spallanzani (1729-1799) mainly for his controversy with Needham over spontaneous generation, but he was a man of multiple scientific activities in the fields of biology, mineralogy, physics, mathematics and... volcanology! Called "the biologist of biologists", he developed a series of investigations about reproduction of amphibian, in one of them -Experiences in service to the history of the generation of animals and plants- we have found horrific experiments with frogs, including severe and useless mutilation of males, in order to interrupt its copulation with females, acts he describes as "barbaric", and we estimate inadmissible in the ecclesiastic man he was, even in an epoch in which animals were considered "anima vili" (something without value). A brief review of the use of animals in laboratories shows significant advances in the ethical regulations for this practice, but we believe that these achievements are not enough.
\end{abstract}

Keywords: Spallanzani; frog; fecundation; animal suffering.

animales, todos los cuales veremos de uno en uno a partir de la lectura de una de sus publicaciones más célebres, "Experiencias para servir a la historia de la generación de animales y plantas" (Figura 1).

\section{El biólogo de los biólogos}

Siendo fundamentalmente un biólogo, lo desparramado de sus intereses, reflejado en la diversidad de sus experiencias y publicaciones, viene a demostrar que sus inquietudes iban más allá de la medicina: cuando el conocimiento científico y humanístico era tan poco, no era 
extraño encontrar hombres universales como éste, que sabían de todo, a diferencia de hoy, en que el conocimiento es tanto que lleva forzosamente a la especialización. Así, podemos entender que haya sido Profesor de Física y Matemáticas en la Universidad de Reggio Emilia y Profesor de Logia y Metafísica, en la Universidad de Módena; Director del Museo de Historia Natural en Pavía, para el cual buscó incesantemente muestras biológicas y minerales; que haya realizado y publicado investigaciones sobre la generación espontánea, teoría que pudo desacreditar como falsa, así como sobre la fecundación en animales; varias más sobre la digestión y la circulación en el hombre y la orientación de los murciélagos mediante el eco; todo esto sin mencionar sus observaciones en mineralogía y en vulcanología, que inmortalizaron su nombre en un cráter de la Luna ${ }^{2,3}$.

Otra muestra de la amplitud de sus conocimientos y habilidades la proporciona su estilo literario, caracterizado por su claridad y amenidad, que contribuyeron grandemente a la aceptación y éxito de sus publicaciones, como lo muestra el comienzo de unos de sus libros:

Llamo verde a la rana de que voy a hablar, porque la parte superior de su cuerpo está teñida de este color de una manera más o menos marcada; y la llamo acuática porque habita en las aguas, sobre todo en las de los pantanos donde crece el arroz y en las zanjas; la distingo, pues, de las ranas que habitan en la tierra y de las que se encuentran en los árboles, de que hablaré en el capitulo segundo. Esta cita es de una excelente versión en español de Fernando Barranco Díaz, en la página 13 del libro que hemos leído, que se aproxima bastante al original italiano, en tanto que las traducciones inglesas son más bien pobres.

\section{El abate}

¿Era Spallanzani en verdad un eclesiástico? La Real Academia Española de la Lengua entrega la siguiente definición de "abate", aclarando que viene del italiano abate, que significa "abad", y ésta del latín tardío abbas, con tres acepciones:

1. Presbítero extranjero, especialmente francés o italiano, y también eclesiástico español que ha residido mucho tiempo en Francia o Italia.

2. Eclesiástico de órdenes menores, y a veces simple tonsurado, que solía vestir traje clerical a la romana.

3. Clérigo dieciochesco frívolo y cortesano.

¿En cuál de estas acepciones encaja nuestro abate? Seguramente no la tercera, pues aunque era dieciochesco, sus actividades científicas nada tenían de frívolas, dejándonos entonces la duda entre la primera y la segunda.

Ahora bien, considerando la jerarquía de la Iglesia Católica que se nos enseñara en la escuela, basada en

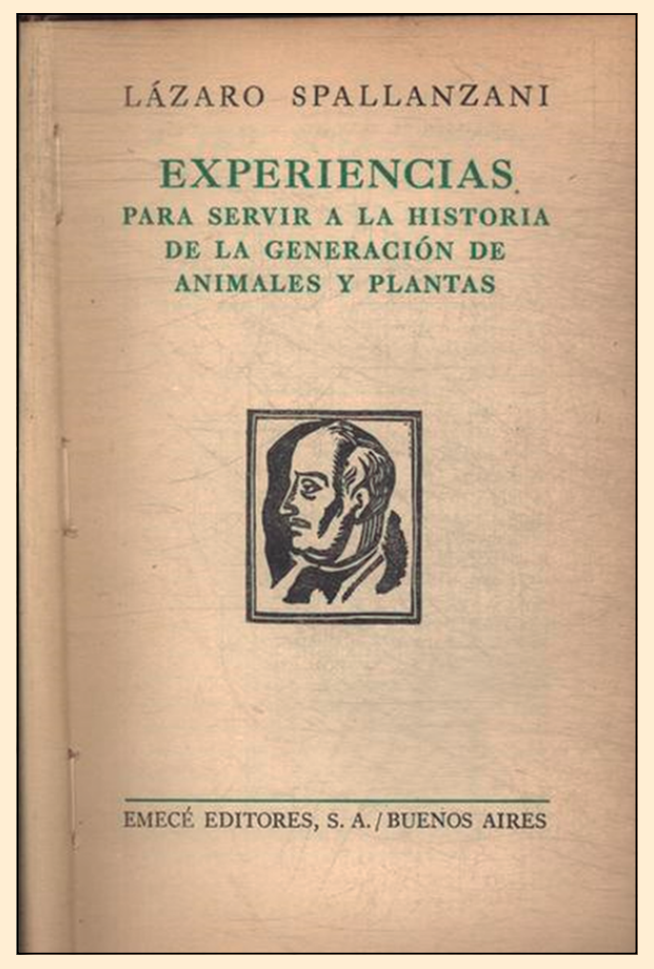

Figura 1. Texto comentado en este artículo. los tres grados descendentes del sacramento del orden, Episcopado, Presbiteriado y Diaconado, tenemos en la cumbre al Papa, luego a los cardenales, los primados, los arzobispos, los obispos, los presbíteros y los diáconos. Quedémonos, por comodidad, con la primera acepción y consideremos a nuestro abate un presbítero extranjero. Recordemos de paso que en Chile tenemos una figura que bien puede competir con Spallanzani en cuanto a la multiplicidad de sus conocimientos e investigaciones, el abate Juan Ignacio Molina, justamente llamado así por haber vivido largo tiempo en Italia, donde fue catedrático en la Universidad de Bolonia, cuya obra quizás les presentemos en otra ocasión.

Volviendo a nuestro sujeto, enfrentemos la angustiosa pregunta central: ¿Cómo compatibilizaba un eclesiástico ciencia con religión y como podía un seguidor de Cristo ser tan cruel con quienes San Francisco llamara sus hermanos, aunque menores, pero hermanos al fin y al cabo? Mal pudiera alegar ignorancia, pues el santo de Asís llevaba ya canonizado cinco siglos y era también italiano.

Más, para que el lector comparta nuestras inquietudes, es preciso ponerle en conocimiento de los horripilantes experimentos realizados in anima vili, que en la actualidad hubieran espantado a nuestros comités de ética de la investigación, y que en caso alguno podrían justificarse alegando amor a la ciencia, pues aceptarlos sería el primer paso, leve pero decisivo, para deslizarnos por una peligrosa pendiente que pudiera llevarnos a la 
Figura 2. Estatua de Lazaro Spallanzani observando una rana (Scandiano, Italia).

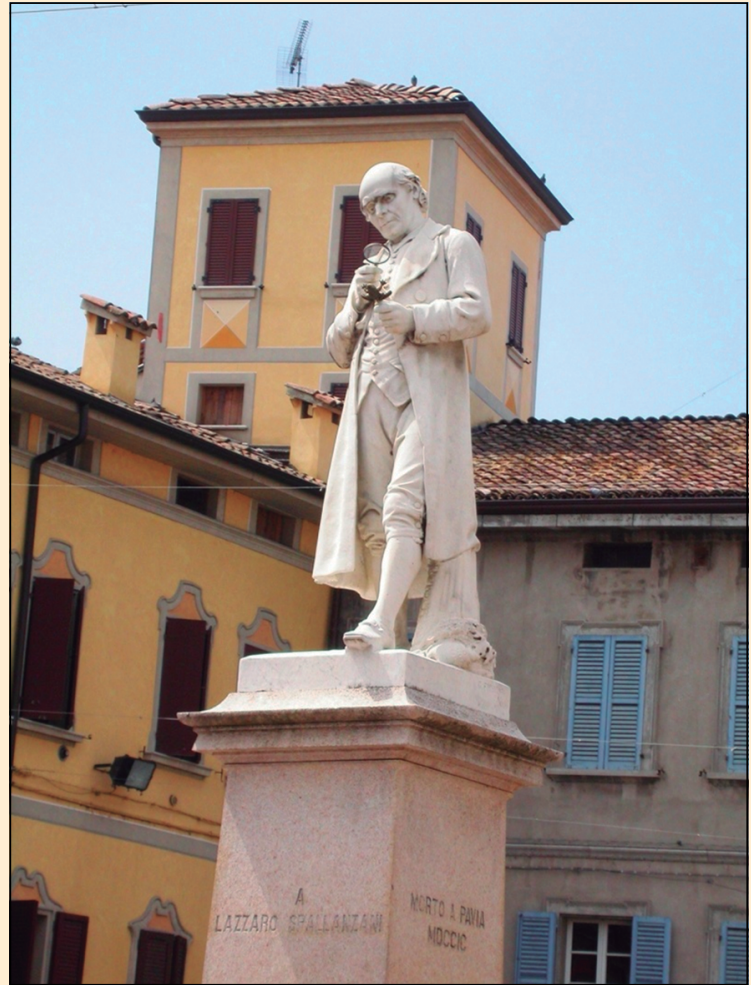

absolución de Mengele. Par exemple !... exclamaría Pasteur, exclamación cuyo significado puede ir más allá del literal (Figura 2).

\section{Un hombre bárbaro}

Los párrafos citados a continuación están tomados de la Memoria Primera, que trata De la generación de algunos animales anfibios, específicamente del "sapo fétido terrestre" y del "sapo de ojos rojos con tubérculos dorsales", como los define Spallanzani, quien dice:

Muchos naturalistas, como Swammerdam, creen que la cópula del sapo dura cuarenta días; se cree lo mismo respecto de las ranas. En los países templados, como la Lombardía, la cópula de la rana dura algunas horas, la de las ranas acuáticas se prolonga aproximadamente durante una semana, y la de las otras especies de sapos durante un tiempo más largo, a causa de la estación fría en que se acoplan.

Tras estas consideraciones inicia Spallanzani sus experiencias con el sapo fétido terrestre, que vive en la tierra pero que, por comodidad, hace el amor en el agua, algo similar a los sibaritas que lo hacen sobre un colchón hidráulico.

El abate ponía en un vaso una pareja de esta especie y observaba la cópula día a día. Al abrir una hembra a las doce horas encontraba que los huevos aun no habían abandonado el ovario; en otra, sacrificada a los dos días y medio, observaba lo mismo; a los tres días los huevos estaban en el oviducto y al cuarto todos estaban en el útero, rodeados de un mucílago. Al quinto día los óvulos, formando cordoncitos, eran expulsados al agua y el macho eyaculaba sobre ellos, probando así el investigador que la fecundación se hacía afuera de la hembra. Con mucho sentido del humor, nos parece, puso calzones de tafetán a un sapo para "dificultarle la operación" y los huevos no fueron fecundados, ocurriendo lo mismo si el macho, fatigado, se retiraba antes de la expulsión.

A continuación, pide unas curiosas disculpas a sus hipotéticos lectores: Tal vez las personas delicadas habrán experimentado alguna repugnancia al oír hablar de los sapos, de esos animales tan feos en apariencia, y hubieran preferido que se les hablase de animales más agradables o que se tocan con placer, pero el naturalista no tiene ninguna predilección en las producciones de la Naturaleza y las observa todas indiferentemente. ¡Qué burla más siniestra, porque la repugnancia viene ahora!

Hasta aquí nuestro naturalista sólo había sacrificado algunas hembras, para observar el proceso desde que los óvulos salían del ovario hacia el útero y luego hacia el agua: consideremos que en experiencias secuenciales en la actualidad se sigue matando ("sacrificando" suena más bonito) peces, ratoncillos y cobayos, para no citar animales más grandes, que son más caros y gritan más fuerte, amén que los simios tienen rasgos humanos y mirada tierna. Más, a partir de este momento, el demonio parece haberse apoderado del buen abate, quien comienza a ejecutar una serie de siniestras torturas sobre los machos, para ver si dejan de copular, malditos pecadores, y sueltan a las pobrecillas hembras violadas a porfía. Pero mejor dejemos la palabra al investigador:

Este ardor obstinadamente constante de los sapos machos en sus prolongadas cópulas, me ha dado ocasión de algunas experiencias cuyos resultados serán tal vez examinados con curiosidad (morbosa, aclaramos nosotros). Si los sapos de ojos rojos y tubérculos dorsales huían durante la cópula saliendo de mis vasos llenos de agua para ponerse en seco, la hembra llevaba siempre al macho, que no la soltaba. En vano le he tenido suspendido durante un cuarto de hora de una pata atada a un hilo; por muy penosa que fuera esta postura no le distrajo, y el peso de la hembra, más grande que el suyo y que debía sostener, no le hizo ceder. Ensayé herirle con una aguja, ya en las patas posteriores, ya en los muslos, ya sobre el lomo y los costados, ya incluso en la cabeza. La sangre corria, las heridas le provocaban contracciones, pero él no abandonaba a su hembra, que estrechaba siempre con fuerza.

¿Podríamos nosotros mostrar un amor más grande? Seguramente no. Menos el abate, que sigue adelante en 
produce la fecundación e impregnación del huevo fuera del cuerpo materno"4. Pero olvida cómo, al continuar sus observaciones después de la fecundación, comete un error del cual no puede estar orgulloso: no disponiendo de microscopios adecuados, mal podía ver al espermatozoide penetrar en el óvulo, y sostenía, por consiguiente, que los huevos que veía expulsar a la hembra reunidos en cordones eran los guarisapos preformados, describiendo minuciosamente la metamorfosis que iban sufriendo de huevo a sapo. ¿Pensaba, quizás, que el semen, materia que demoraría buen tiempo en ver, constituía un espíritu vital que, regando el exterior del huevo, echaba a andar su motorcito interior? Este espíritu vital para nosotros, simples cronistas, existe, siendo el impulso irresistible que lleva a las especies a perpetuarse sin cesar, el mismo que movía al pobre animal mutilado por el abate para aferrarse a la hembra y consumar la fecundación; espíritu que debe existir en cada célula y en cada proteína, desde la prion a la sabandija, propiciando, en conjunto con el medio ambiente, la evolución de las especies.

Las mutilaciones perpetradas por Lázaro Spallanzani en nuestros hermanos menores son, pura y simplemente, perversas. Invitamos a nuestros lectores varones que estén en desacuerdo con esta calificación, a imaginarse en la situación de los pobres sapos de ojos rojos y tubérculos dorsales. Como dice Nicolás Guillén ${ }^{5}$, en una elegía a un niño negro en Little Rock:

\section{Pensad por un momento imaginadlo un solo instante.}

La experimentación con animales no era una novedad en la época de nuestro abate; por el contrario, constituía una práctica muy antigua, aunque restringida en comparación con los tiempos actuales, en que más de cien millones de animales vertebrados se utilizan con estos fines, aunque Spallanzani podría argumentar, si estuviera en nuestros tiempos, que los sapos son invertebrados; bromas aparte, considerando solo ratas y ratones se empleaban en laboratorios de Estados Unidos, ya a principios de siglo, unos 80 millones al año ${ }^{6}$, de los cuales hasta los sobrevivientes suelen ser sacrificados, uso masivo que se desató a raíz del desastre de más de cien personas fallecidas a causa de un "elixir" de sulfanilamida en $1937^{7,8}$ que impulsó al Congreso a legislar para que las compañías farmacéuticas realizaran ensayos toxicológicos de sus productos en animales antes de ser usados en humanos: Ley Federal de Alimentos, Medicamentos y Cosméticos, 1938. Antes de ésta, desde 1860, en dicho país se venían formando agrupaciones contra la crueldad en animales y la vivisección, impotentes ante el poder del gremio médico y de la industria farmacéutica.

Los defensores del uso de animales en laboratorio hablan de "experimentación"; sus detractores usan el 
término peyorativo de "vivisección", es decir, disección sobre un ser vivo, generalmente animal, pero que algunos médicos soberbios alguna vez han aplicado a un congénere, como se narra en la siguiente anécdota que, mítica o cierta, es muy decidora:

Muretus, humanista francés del siglo XVI, habiendo huido de Francia acusado de sodomía y herejía (que hoy no son crímenes), cayó enfermo en Lombardía y los médicos que lo atendieron, viéndolo pobremente vestido lo trataron despectivamente diciéndose: Faciamus experimentum in anima vili. Y el vagabundo estimado "sin valor", replicó en perfecto latín: ¿Villem animan appellas pro qua Christus non dedignatus est mori? Es decir, "¿llamáis sin valor a alguien por quien Cristo no desdeñó morir??

En fin, no era la finalidad de este artículo la historia de la experimentación en animales: bástenos señalar que infinidad de regulaciones para el empleo en laboratorio de nuestros hermanos menores se han ido estableciendo desde el desastre del elixir de sulfanilamida, con la reducción paulatina de esta práctica, culminando en 1985 cuando el Council for International Organizations for Medical Sciences y el International Council for Laboratory Animal Science establecieron sus principios conjuntamente en 1985, actualizándolos en diciembre del $2012^{10}$, que fueron seguidos primero por los institutos estatales y luego por la industria farmacéutica, en la medida de lo posible, como lo ha hecho Shiseido, el gigante de la cosmética en Japón, al eliminar el 2013 toda prueba en animales de sus productos dentro y fuera del país ${ }^{11}$.

Pese al desánimo que suelen causar las brutalidades que los hombres siguen cometiendo en nuestros días hasta en los países más civilizados, como invasiones injustificadas, guerras religiosas de exterminio con matanza de inocentes, desplazamiento de expatriados y torturas con los prisioneros, es indiscutible que ha habido desde los tiempos pretéritos hasta ahora una progresiva estipulación y regulación ética, estableciendo normas sobre el respeto a los derechos de los humanos y de los animales; más, si éstas se descuidan o se ignoran, y algún investigador científico retrocede al siglo de Spallanzani, en que a los animales se les suponía un anima vili, es decir, ninguna, puede aparecer un mono que lo salude, no más entrando al laboratorio, advirtiéndole:

- Hermano Francisco, no te acerques mucho... ${ }^{12}$.

\section{Referencias bibliográficas}

1.- Spallanzani L. Experiencias para servir a la historia de la generación de animales y plantas. Memoria Primera: De la generación de algunos animales anfibios. Traducción de F. Barranco. Emecé Editores, S.A., Buenos Aires 1945; pp. 13, 55-103.

2.- Mille Anni di Scienza in Italia. Biografie. Lazzaro Spallanzani. www.imss.fi.it/millean/cronologia/biografie/ spallanzani.html.

3.- International Astronomical Union (IAU) and Working Group for Planetary System Nomenclature (WGPSN). Gazetteer of Planetary Nomenclature. Spallanzani moon crater. https:// planetarynames.wr.usgs.gov/Feature/5662.

4.- Artedi P. Ichtylogie; II:32. Ver: Artedi, Peter. Encyclopaedia Britannica. Ed. Cambridge Universitary Pres, 11th. Ed; 2: 663.

5.- Guillén N. Little Rock. En: La paloma de vuelo popular. Elegías. Editorial Losada. S.A., Buenos Aires 1948; pp. 33-34.

6.- Carbone L. What Animals Want. Oxford University Press, 2004. p. 26

7.- $\quad$ Medicine Post-mortem. Time, December 20, 1937.

8.- Wallace reveals how Federal Agents traced elixir to halt fatalities. The New York Times, November 26, 1937.

9.- Rojas M. Estudios bíblicos. Estudiosbiblicosrojas.blogspot. com/2008/09/anima-vili.html.

10.- International Guiding Principles for Biomedical Research Involving Animals. CIOMS \& ICLA, December 2012.

11.- Efe. Portavoz Shiseido. https:/www.publico.es/actualidad/ empresa-cosmetica-lider.Japon-deyra html

12.- Darío R. Los motivos del lobo. En: Acereda, A. (Editor). Rubén Darío y su sed de ilusiones infinita. Lumen, Barcelona 2000; Poesía 117. 